\title{
Hip fractures among the elderly in Kyoto, Japan: a 10-year study
}

\author{
Maki Asada ${ }^{1,2} \cdot$ Motoyuki Horii $^{1,2,3} \cdot$ Kazuya lkoma $^{2} \cdot$ Tsuyoshi Goto $^{2} \cdot$ Naoki Okubo $^{2} \cdot$ Nagato Kuriyama $^{4}$. \\ Kenji Takahashi ${ }^{2}$
}

Received: 4 August 2020 / Accepted: 6 January 2021 / Published online: 12 February 2021

(C) The Author(s) 2021

\begin{abstract}
Summary In Kyoto Prefecture, Japan, the number of hip fractures increased during 2013-2017 compared to 2008-2012. However, the estimated overall incidence rate increased only in femoral neck fractures in men aged $\geq 75$ and women aged $\geq 85$. Purpose The incidence rate of hip fractures in Japan has plateaued or decreased. We investigated the annual hip fracture occurrences in Kyoto Prefecture, Japan, from 2008 to 2017.

Methods Patients aged 65 years and above who sustained hip fractures between 2008 and 2017 and were treated at one of the participating 11 hospitals were included. The total number of beds in these institutions was 3701, accounting for $21.5 \%$ of the 17,242 acute-care beds in Kyoto Prefecture. The change in incidence rate was estimated utilizing the population according to the national census conducted in 2010 and 2015.

Results The total number of hip fractures was 10,060, with $47.5 \%$ femoral neck fractures and $52.5 \%$ trochanteric fractures. A decrease in number was seen only in trochanteric fractures in the group of 75- to 84-year-old women. The population-adjusted numbers of femoral neck fractures showed a significant increase in all age groups in men, whereas in women, there was an increase in femoral neck fractures in the $\geq 85$ group and trochanteric fractures in the age group $65-74$, and a decrease in trochanteric fractures in the age group 75-84. The estimated change in incidence rate showed an increase in femoral neck fractures in men aged $\geq 75$ and women aged $\geq 85$.

Conclusion In Kyoto Prefecture, the number of hip fractures increased in the second half of the study period (2013-2017) compared to the first half (2008-2012). However, the incidence rate had not increased, except in femoral neck fractures in men aged $\geq 75$ and women aged $\geq 85$.
\end{abstract}

Keywords Hip fracture $\cdot$ Femoral neck fracture $\cdot$ Trochanteric fracture $\cdot$ Incidence

\section{Introduction}

The number of hip fractures continues to grow in Japan with the aging population. However, the incidence rate has been reported to have slowed down in growth and decreased in both

Maki Asada

kusaka@koto.kpu-m.ac.jp

Rakuwakai Otowa Rehabilitation Hospital, Kyoto, Japan

2 Department of Orthopaedics, Graduate School of Medical Science, Kyoto Prefectural University of Medicine, Kyoto, Japan

3 Department of Rehabilitation Medicine, Graduate School of Medical Science, Kyoto Prefectural University of Medicine, Kyoto, Japan

4 Department of Epidemiology for Community Health and Medicine, Graduate School of Medical Science, Kyoto Prefectural University of Medicine, Kyoto, Japan men and women aged 70-79 years [1]. A decrease in the incidence rate of hip fractures has also been noted in many Western countries.

Hip fractures can be divided into femoral neck fractures which are intraarticular and trochanteric fractures which are extraarticular. Literature shows that discrepancies in their incidence rates exist with differences in geography, age, height, bone density, and vertebral fracture complication rates [2]. Hagino et al. [3] reported a recent increase in the ratio of patients with femoral neck fractures to those with trochanteric fractures (the $\mathrm{N} / \mathrm{T}$ ratio).

In order to improve prevention strategies for hip fractures in the prefecture of Kyoto Japan, where the incidence rate of hip fractures is more than 1.2 times that of the national rate [1], we started a 10-year study on hip fractures using registration forms in accordance with the nationwide survey of the Japanese Orthopaedic Association (JOA) [4]. We hypothesized that hip 
Fig. 1 a, b The change in the population over 65 in Kyoto Prefecture between 2010 and 2015. The curve shows the rate of increase or decrease calculated by the population in 2015 divided by that in 2010



Table 1 The number of hip fractures and N/T ratio in the first and second half of the study period. Incidences in each sex and age group are shown. Significant increases/decreases in the second 5 years are shown by bold type. N/T signifies the rate of femoral neck fractures divided by trochanteric fractures

\begin{tabular}{|c|c|c|c|c|c|c|c|c|c|c|c|c|c|}
\hline & \multirow[t]{2}{*}{ Age group } & \multicolumn{3}{|c|}{ Hip fracture } & \multicolumn{3}{|c|}{ Femoral neck fracture } & \multicolumn{3}{|c|}{ Trochanteric fracture } & \multicolumn{3}{|l|}{$\mathrm{N} / \mathrm{T} * *$} \\
\hline & & First* & Second & $p$ & First & Second & $p$ & First & Second & $p$ & First & Second & $p$ \\
\hline \multirow[t]{3}{*}{ Male } & $65-74$ & 150 & 205 & 0.000 & 71 & 120 & 0.000 & 79 & 85 & 0.500 & 0.899 & 1.412 & 0.037 \\
\hline & $75-84$ & 390 & 484 & 0.000 & 172 & 252 & 0.000 & 218 & 232 & 0.343 & 0.789 & 1.086 & 0.019 \\
\hline & $\geq 85$ & 304 & 480 & 0.000 & 116 & 227 & 0.000 & 188 & 253 & 0.000 & 0.617 & 0.897 & 0.012 \\
\hline \multirow[t]{3}{*}{ Female } & $65-74$ & 394 & 511 & 0.000 & 273 & 337 & 0.000 & 121 & 174 & 0.000 & 2.256 & 1.937 & 0.288 \\
\hline & $75-84$ & 1387 & 1394 & 0.851 & 746 & 784 & 0.164 & 641 & 610 & 0.221 & 1.164 & 1.285 & 0.193 \\
\hline & $\geq 85$ & 1920 & 2414 & 0.000 & 691 & 960 & 0.000 & 1229 & 1454 & 0.000 & 0.562 & 0.660 & 0.011 \\
\hline \multirow[t]{3}{*}{ All } & $65-74$ & 544 & 716 & 0.000 & 344 & 457 & 0.000 & 200 & 259 & 0.000 & 1.720 & 1.764 & 0.829 \\
\hline & $75-84$ & 1777 & 1878 & 0.017 & 918 & 1036 & 0.000 & 859 & 842 & 0.562 & 1.069 & 1.230 & 0.034 \\
\hline & $\geq 85$ & 2224 & 2894 & 0.000 & 807 & 1187 & 0.000 & 1417 & 1707 & 0.000 & 0.570 & 0.695 & 0.001 \\
\hline
\end{tabular}

" "First" means the first half of the period (2008-2012) and "second" means the second half of the period (2013-2017)

${ }^{* *} N / T$, the ratio of patients with neck fractures to those with trochanteric fractures

Bold numbers indicate significant differences between the first and second half of the period $(p<0.05)$ 
Table 2 Comparison of the N/T ratio* in the first and second half of the period in nationwide Japan

\begin{tabular}{llll}
\hline Period** & \multicolumn{2}{l}{ First } & Second \\
\hline Male & $65-74$ & $1.181(7709 / 6528)$ & $1.392(9955 / 7152)$ \\
& $75-84$ & $0.915(14,853 / 16,236)$ & $1.067(19,189 / 17,992)$ \\
& $\leq 85$ & $0.746(10,166 / 13,624)$ & $0.823(16,330 / 19,836)$ \\
Female & $65-74$ & $2.110(21,160 / 10,029)$ & $2.515(25,389 / 10,094)$ \\
& $75-84$ & $1.060(54,685 / 51,596)$ & $1.178(62,173 / 52,776)$ \\
& $\leq 85$ & $0.596(53,138 / 89,198)$ & $0.609(71,611 / 11,7496)$ \\
\hline
\end{tabular}

${ }^{*} N /$ T ratio, the ratio of patients with femoral neck fractures to those with trochanteric fractures

** Period: "First" means the first half of the period (2008-2012) and "second" means the second half of the period (2013-2017)

The analysis was based on the hip fracture data distributed annually by the Japanese Orthopedic Association

The figures in parentheses indicate the actual number of occurrences

For all items, there are significant differences between the first and second half of the period (chi-square test $p<0.0005$ )

fractures in Kyoto would also show a decrease in the rate of growth.

\section{Materials and methods}

This was a retrospective, multicenter, observational study. Eleven JOA-authorized hospitals in Kyoto Prefecture, Japan, were involved. The total number of beds in these institutions were 3701 , accounting for $21.5 \%$ of the 17,242 acute-care beds in Kyoto Prefecture.

Patients aged 65 years or older who sustained hip fractures between January 1, 2008, and December 31, 2017, and were treated at one of the participating hospitals were included. Patients with isolated greater trochanteric, subtrochanteric, or pathologic fracture were excluded.

The following data were obtained using registration forms from a JOA nationwide survey $[4,5]$ : sex, age, and fracture type (femoral neck vs. trochanteric). The diagnoses were made by board-certified orthopedic surgeons. Ages were categorized as $65-74,75-84$, or $\geq 85$ years.

The study period was divided into the first 5 years (20082012), hereafter referred to as the first half, and the last 5 years (2013-2017) referred to as the second half. The numbers of femoral neck fractures and trochanteric fractures were compared between the two periods by sex as well as age group.

In addition, to estimate the rate of change in incidence, the population-adjusted number of hip fractures (adjusted number) in the second half of the period was calculated, applying the demographics in the 2010 and 2015 census (Fig. 1) as the population of the first half and second half. To be specific, the number of hip fractures in the second half was divided by the ratio of the change in population between the first and second half. Then the number of fractures in the first half was divided by this adjusted number of fractures in the second half in each age group, in order to estimate the rate of change in incidence from the first to the second half of the study period. These population adjustments were made using the actual incidence and demographic changes for every 5 years of age. Using the hip fracture data distributed annually by the Japanese Orthopedic Association, we calculated the nationwide N/T ratio for reference in the first and second half of this study.

Ethical approval was obtained from the ethics committee of the Kyoto Prefectural University of Medicine.

The statistical comparison was made using the Poisson distribution, and a $p$ value of 0.05 or less was considered a significant difference. The chi-squared exam was used to compare the N/T ratio. Statistical analyses were conducted with StatFlex ver 6.0 (Artech Co., Ltd., Osaka, Japan).

\section{Results}

The total number of hip fractures was 10,060 , with 4776 (47.5\%) femoral neck fractures and $5284(52.5 \%)$ trochanteric fractures. The percentages of women were $79.9 \%$ in femoral neck fractures and $80.0 \%$ in trochanteric fractures. Table 1 shows the number of hip fractures in the first and second half. Only trochanteric fractures in the 75- to 84-year-old group in women had decreased in number.

An increase in population from 2010 to 2015 in all ages of 65 and above in both sexes was seen by plotting the population according to the national census (Fig. 1). Figure 2 shows the number of fractures in the first half and the populationadjusted number in the second half. The adjusted numbers of femoral neck fractures show a significant increase in all age groups in men. In women, the adjusted number of femoral neck fractures in the over- 85 group and adjusted number of trochanteric fractures in the age group 65-74 increased, whereas the adjusted number of trochanteric fractures in the age group 75-84 decreased. The N/T ratio increased in the second half in all age groups in men, and in the over- 85 group in women (Table 1). The nationwide N/T ratio in the first and second half of this study (Table 2) showed an increase in all age groups in both sexes.

\section{Discussion}

The incidence rates of hip fractures have been reported to be decreasing globally [6-9] as well as in Japan $[1,10,11]$. This trend has been attributed to promotion of health programs to prevent falls $[7,8,12]$, changes in lifestyle [8], and the wider use of anti-osteoporotic drugs $[1,6,8-11,13]$. 

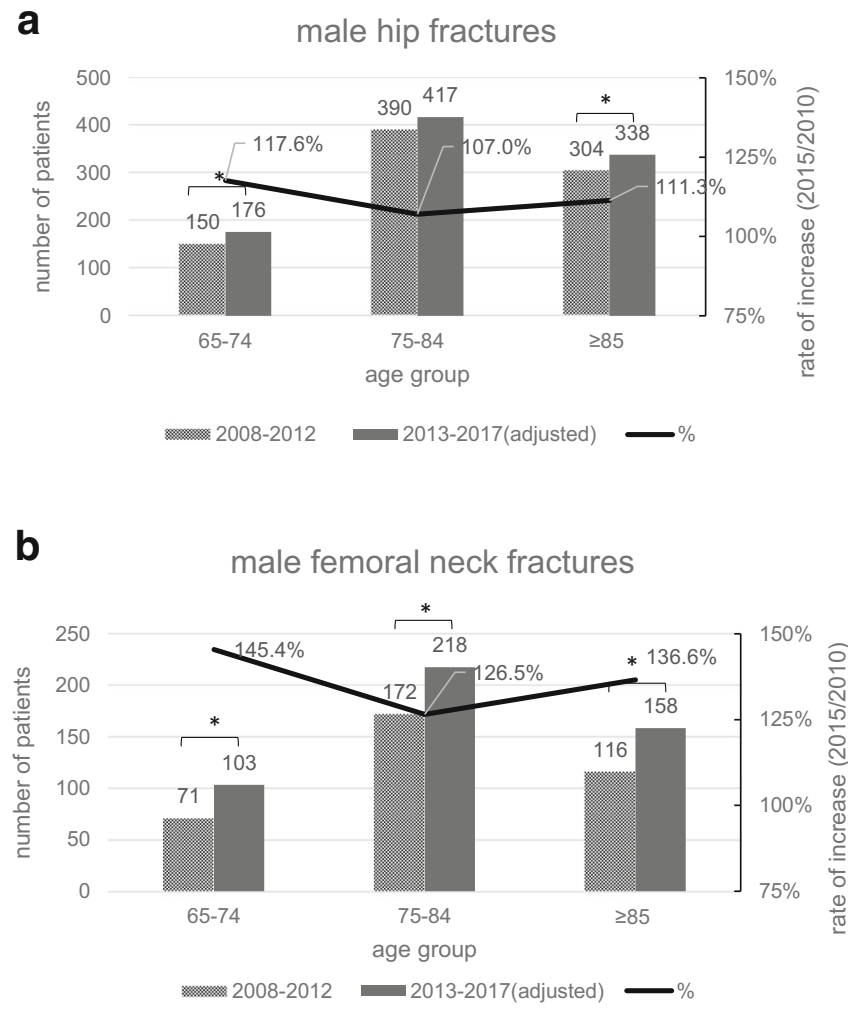

C

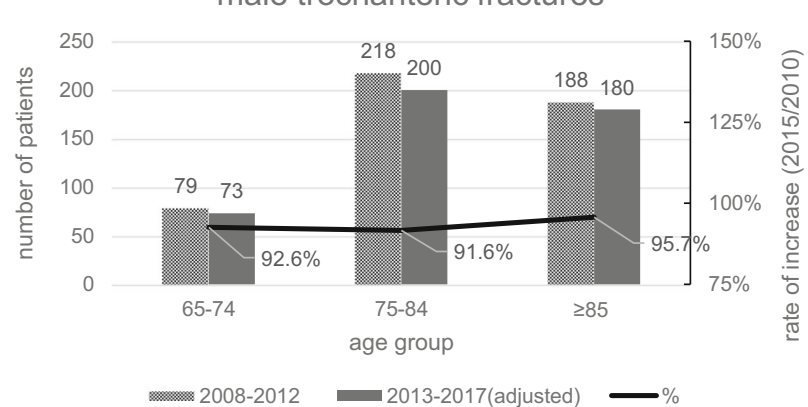

d

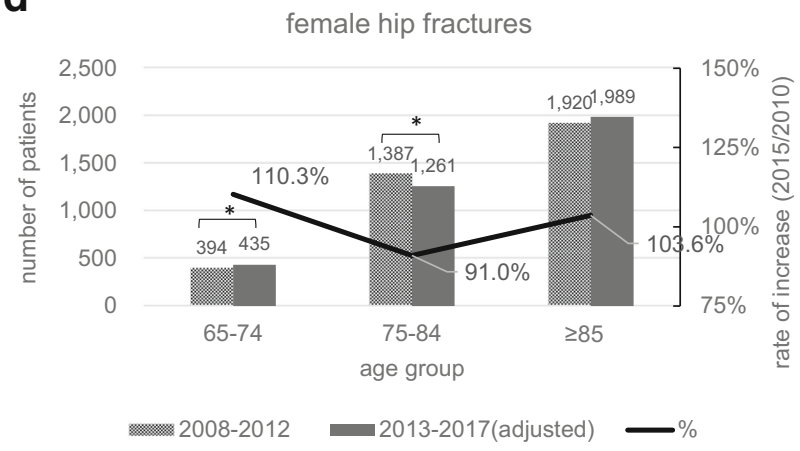

e

female femoral neck fractures

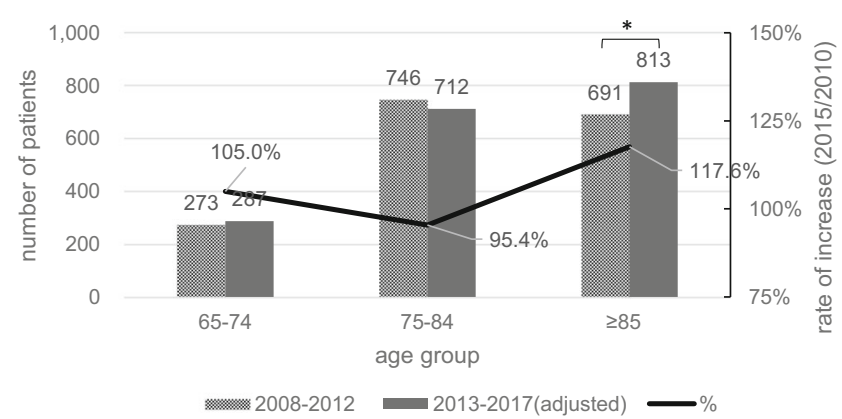

f

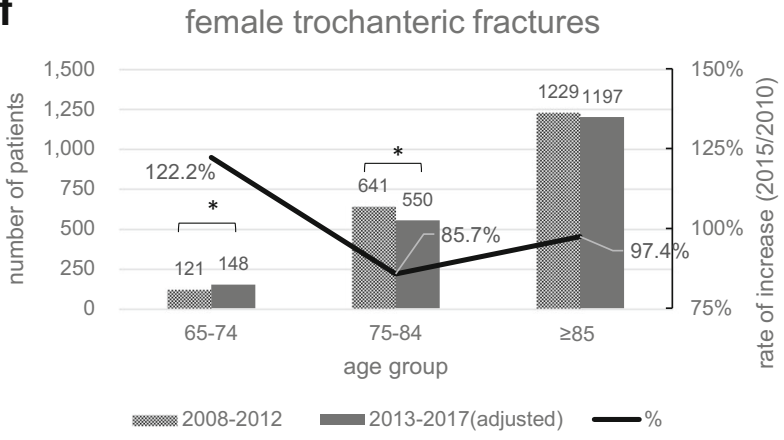

Fig. 2 a-f Comparison of the number of hip fractures in the first and second half of the study period with adjustment for the population. The curve shows the rate of increase or decrease calculated by the population in 2015 divided by that in 2010 . Asterisks show significant differences

Meanwhile, Hagino et al. [3] have reported the relative increase of femoral neck fractures in comparison to trochanteric fractures in Japan. The N/T ratio in the first and second half of this study showed a nationwide increasein all age groups in both sexes. Tamaki et al. reported in a study using the National Health Insurance Claim Database that the agestandardized hip fracture incidence rates indicated no significant change in females and a significant increase in males in Japan from 2012 to 2015 [14]. Gender differences in the trends in fracture incidence have also been noted, with a decrease in fracture incidence in females relative to males over the last 20 years [15].

Our study showed the number of hip fractures in Kyoto prefecture significantly increased in the second half of the study period in all groups except in women aged 75-84. In men, femoral neck fractures increased in all age groups, but trochanteric fractures increased only in the over- 85 group. Although it is impossible to calculate the exact incidence rate in this study, by applying the change in the population, the change in incidence rate can be estimated. Taking demographics into account, the population-adjusted estimated number of hip fractures significantly decreased in women aged 75-84, largely due to the reduction in trochanteric fractures. On the other hand, the population-adjusted number of hip fractures in men did not decrease. By fracture type, trochanteric fractures did not increase, while femoral neck fractures increased significantly in each age group.

Our study indicated a difference in the trend of incidence by gender and fracture type. It also suggested that the current treatment and or prevention strategies being taken may be 
insufficient with regard to femoral neck fractures. Femoral neck fractures have been reported to occur in taller, younger individuals with higher bone densities and in more urban settings, compared to trochanteric fractures [2]. Because age had increased within the 10-year period, the change in the pattern of hip fractures in Kyoto could be a reflection of changes in any of the remaining factors. The study period coincides with the increased use of bisphosphonates in Japan, and although bisphosphonates have been shown to decrease hip fractures $[16,17]$, they are also known to increase bone density, and their generalized use may have had a greater preventive effect on trochanteric fractures compared to femoral neck fractures. Further investigation into the factors affecting hip fracture patterns in Kyoto should lead to more effective prevention strategies, taking into account bone quality for example.

One of the limitations of this study is that the actual incidence rate data could not be obtained. We tried to minimize this weakness by adjusting for a population for each 5-year age group in order to obtain a more accurate estimation of the rate of change in incidence. Another limitation is that confounding factors such as complications, history of corticosteroid use, and body figure are unknown. Needless to say, a coverage closer to $100 \%$ of the acute beds of the prefecture would have been preferable, rather than the $21.5 \%$ that we were able to obtain. On the other hand, all institutions involved were JOA-authorized hospitals, and data were collected by orthopedic surgeons, so a more accurate diagnosis of fracture type could be expected.

In conclusion, there was an increase in the number of hip fractures in Kyoto prefecture, Japan, in the second half of the study period (2013-2017) compared to the first half (20082012). However, the estimated overall increase in incidence rate was subdued, with the exception of femoral neck fractures in men aged 75 and above and women aged 85 and above which increased.

Acknowledgments The authors would like to thank the following for their invaluable help and contribution to the study by registering their cases at each institution: North Medical Center Kyoto Prefectural University of Medicine, Maizuru Red Cross Hospital, Fukuchiyama City Hospital, Ayabe City Hospital, Kyoto Chubu Medical Center, Japanese Red Cross Kyoto Daiichi Hospital, Japanese Red Cross Kyoto Daini Hospital, Rakuwakai Marutamachi Hospital, Kyoto Kuramaguchi Medical Center, Kyoto Kizugawa Hospital, Tanabe Central Hospital.

Author contribution MA, MH, NK, KI, and KT contributed to the conception and design of the study.

MA, MH, TG, and NO participated in data collection.

$\mathrm{MH}$ and NK performed the statistical analysis.

MA, MH, and KI drafted the manuscript. All authors read and approved the final manuscript.

\section{Declarations}

Ethics approval All procedures performed in studies involving human participants were in accordance with the ethical standards of the institutional and/or national research committee and with the 1964 Helsinki declaration and its later amendments or comparable ethical standards. Ethical approval was obtained from the ethics committee of the Kyoto Prefectural University of Medicine.

Consent to participate For this type of study, formal consent is not required.

\section{Conflicts of interest None.}

Open Access This article is licensed under a Creative Commons Attribution 4.0 International License, which permits use, sharing, adaptation, distribution and reproduction in any medium or format, as long as you give appropriate credit to the original author(s) and the source, provide a link to the Creative Commons licence, and indicate if changes were made. The images or other third party material in this article are included in the article's Creative Commons licence, unless indicated otherwise in a credit line to the material. If material is not included in the article's Creative Commons licence and your intended use is not permitted by statutory regulation or exceeds the permitted use, you will need to obtain permission directly from the copyright holder. To view a copy of this licence, visit http://creativecommons.org/licenses/by/4.0/.

\section{References}

1. Orimo H, Yaegashi Y, Hosoi T, Fukushima Y, Onoda T, Hashimoto T, Sakata K (2016) Hip fracture incidence in Japan: estimates of new patients in 2012 and 25 -year trends. Osteoporos Int 27(5):1777-1784. https://doi.org/10.1007/s00198-015-3464-8

2. Löfman O, Berglund K, Larsson L, Toss G (2002) Changes in hip fracture epidemiology: redistribution between ages, genders and fracture types. Osteoporos Int 13(1):18-25

3. Hagino H, Endo N, Harada A, Iwamoto J, Mashiba T, Mori S, Ohtori S, Sakai A, Takada J, Yamamoto T (2017) Survey of hip fractures in Japan: recent trends in prevalence and treatment. J Orthop Sci 22(5):909-914. https://doi.org/10.1016/j.jos.2017.06. 003

4. Committee for Osteoporosis Treatment of The Japanese Orthopaedic Association (2004) Nationwide survey of hip fractures in Japan. J Orthop Sci 9(1):1-5. https://doi.org/10.1007/s00776003-0741-8

5. Horii M, Fujiwara H, Ikeda T, Ueshima K, Ikoma K, Shirai T, Terauchi R, Nagae M, Kuriyama N, Kubo T (2013) Urban versus rural differences in the occurrence of hip fractures in Japan's Kyoto prefecture during 2008-2010 a comparison of femoral neck and trochanteric fractures. BMC Musculoskelet Disord 304. https:// doi.org/10.1186/1471-2474-14-304. [PMC free article] [PubMed] [CrossRef] [Google Scholar]

6. Stevens JA, Rudd RA (2010) Declining hip fracture rates in the United States. Age Ageing 39:500-503

7. Icks A, Arend W, Becker C, Rapp K, Jungbluth P, Haastert B (2013) Incidence of hip fractures in Germany, 1995-2010. Arch Osteoporos 8:140

8. Azagra R, Lopez-Exposito F, Martin-Sanchez JC, Aguye A, Moreno N, Cooper C, Diez-Perez A, Dennison EM (2014) Changing trends in the epidemiology of hip fracture in Spain. Osteoporos Int 25:1267-1274

9. Piscitelli P, Feola M, Rao C, Celi M, Gasbarra E, Neglia C, Quarta G, Liuni FM, Parri S, Iolascon G, Brandi ML, Distante A, Tarantino U (2014) Ten years of hip fractures in Italy: for the first time a decreasing trend in elderly women. World J Orthop 5:386-391 
10. Ohta H, Mouri M, Kuroda T, Nakamura T, Shiraki M, Orimo H (2017) Decreased rate of hip fracture and consequent reduction in estimated medical costs in Japan. J Bone Miner Metab 35(3):351353. https://doi.org/10.1007/s00774-016-0760-0

11. Imai N, Endo N, Shobugawa Y, Ibuchi S, Suzuki H, Miyasaka D, Sakuma M (2018) A decrease in the number and incidence of osteoporotic hip fractures among elderly individuals in Niigata, Japan, from 2010 to 2015. J Bone Miner Metab 36(5):573-579. https:// doi.org/10.1007/s00774-017-0863-2

12. Korhonen N, Niemi S, Parkkari J, Sievanen H, Palvanen M, Kannus P (2013) Continuous decline in incidence of hip fracture: nationwide statistics from Finland between 1970 and 2010. Osteoporos Int 24:1599-1603

13. Brauer CA, Coca-Perraillon M, Cutler DM, Rosen AB (2009) Incidence and mortality of hip fractures in the United States. JAMA 302:1573-1579

14. Tamaki J, Fujimori K, Ikehara S, Kamiya K, Nakatoh S, Okimoto $\mathrm{N}$, Ogawa S, Ishii S, Iki M, Working Group of Japan Osteoporosis Foundation (2019) Estimates of hip fracture incidence in Japan using the National Health Insurance Claim Database in 2012-
2015. Osteoporos Int 30:975-983. https://doi.org/10.1007/s00198019-04844-8

15. Abrahamsen B, Laursen HVB, Skjødt MK, Jensen MH, Vestergaard P (2020) Age at hip fracture and life expectancy in Denmark - secular trends over two decades. Bone. 130:115083. https://doi.org/10.1016/j.bone.2019.115083

16. Crisp A, Dixon T, Jones G, Cumming RG, Laslett LL, Bhatia K, Webster A, Ebeling PR (2012) Declining incidence of osteoporotic hip fracture in Australia. Arch Osteoporos 7:179-185. https://doi. org/10.1007/s11657-012-0095-y

17. Hawley S, Leal J, Delmestri A, Prieto-Alhambra D, Arden NK, Cooper C, Javaid MK, Judge A, REFReSH Study Group (2016) Anti-osteoporosis medication prescriptions and incidence of subsequent fracture among primary hip fracture patients in england and wales: an interrupted time-series analysis. J Bone Miner Res 31(11):2008-2015. https://doi.org/10.1002/jbmr.2882

Publisher's note Springer Nature remains neutral with regard to jurisdictional claims in published maps and institutional affiliations. 